\title{
Analysis of The Factors Increasing The Mortality In Emergency Department Following Firearm Injuries
}

\author{
Mehmet Reşit Öncü \\ Emergency Department of Medical School, Van Yüzüncü Yul University, Van, Turkey
}

\begin{abstract}
In this study, we aimed to determine the factors that increase mortality in patients presenting to the emergency department after a gunshot injury.

This is a retrospective study. Between January 2010 and January 2014, 246 cases were reported to the tertiary university emergency department after firearm injury; age, sex, injury site and concomitant organ injuries, consciousness and hemoglobin levels, patient distribution according to months and years, length of stay in emergency department and factors increasing mortality were analyzed.

There were a total of 246 subjects included in the study: $211(85.8 \%)$ males and $35(14.2 \%)$ females. The average age was $29 \pm 13.5$. The distribution of the firearm woundings indicated that they occurred most frequently in August $56(22.7 \%)$. Injury localization was detected as head $53(21.5 \%)$, thorax $35(14.2 \%)$, abdomen $27(10.9 \%)$ and extremity 106(43\%). The accompanying injuries were as follows: 23 cases of hemopenumothorax $(9.3 \%), 20$ cases of intestine perforation in the abdomen $(8.1 \%)$. The states of the patients' consciousness were evaluated using the Glasgow coma scale (GCS). The results were as follows: 31 subjects scored 3-8, 22 patients scored 9-13 and 193 patients scored 14-15. The length of stay in the emergency department was as follows; head and neck 119, thorax 150, abdomen 134, multiple trauma 161 and ex 55.

As a result low GCS and Hb levels and long-term Emergency Department duration increase mortality.
\end{abstract}

Key Words: Emergency service, gunshot wounds, Mortality

\section{Introduction}

Firearm injuries (FAI) can be observed in all the societies. However, they are more common in underdeveloped societies, especially where acts of violence are prominent. The influencing factors in the prevalence of mortality due to firearm injuries are sociocultural factors, socioeconomic state, insufficient legal regulation, immigration, mafia, and acts of terror $(1,2)$. However, FAIs are considerably common in countries where the firearm usage is enabled through legislation, such as the United States of America. FAIs are the second most common cause of death among 15-19 year-olds (3). The rates of homicide in the US are seven times higher compared to the other developed countries. Only in the year 2014, 33.700 people were killed due to FAIs, and approximately 81.000 people received non-fatal injuries (4). Recent studies indicate that the mortality rates due to FAIs are high $(5,6)$.

FAIs still cause a considerable number of deaths and disabilities in Turkey. In Turkey, about 3.000 people die due to firearm injuries every year. According to the autopsy reports of the Forensic Medicine Institution, the rate of FAI range between 8 to $13 \%$ (7). The main reason why the incidences of FAIs are high is because the acts of terror resume in this region and the local population react violently to these incidents.

The extent of the damage that occurred within the organs and the subsequent results are closely associated with the area of injury and the properties of the firearm/bullet. If the vital organs or blood vessels are damaged, the patients usually die before they can reach the healthcare center. In the cases of the patients that come to the emergency rooms, the morbidity and mortality values indicate lifethreatening injuries (depending on the region of the injury). Mortality rates are very high in vital organ injuries. The injuries can cause health and labor force losses for the patients that recover from death, together with important health problems. Our purpose is to determine the factors that influence morbidity and mortality in FAIs and to provide suggestions for preventive measures to decrease mortality rates.

\section{Materials and Methods}

All patients admitted to the emergency department (ED) with gunshot wounds were included in the study. This study was analyzed retrospectively. The files of the patients who applied to Van Yüzüncü Y1l University Dursun Odabaş Medical Center between 
Mehmet Reşit Öncü / Increasing mortality in gunshot wounds

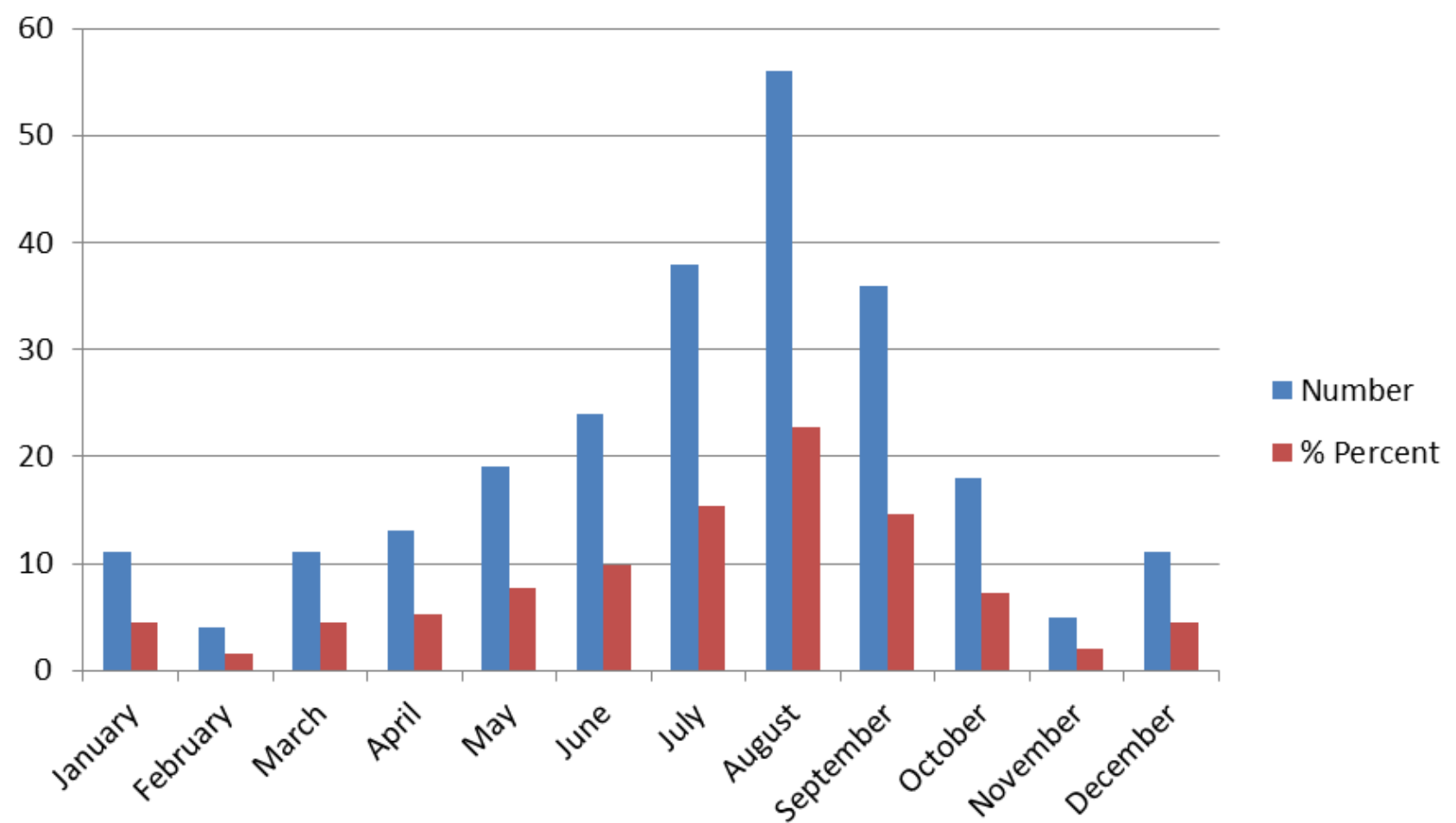

Fig. 1. Total number of gunshot wounds for each month

January 2010 and January 2014 were taken from hospital information system. All kinds of injuries due to firearm injuries were included in the study. There were a total of 246 patients. Data obtained from patients (age, sex, distribution of cases by month and year, wound localization and accompanying organ injuries, GCS and Hb levels, length of stay in the ED were analyzed. For data analysis, the anatomical region was categorized as head and neck, trunk (chest, abdomen and pelvis), upper extremity, lower extremity and multiple (injury involving $\geq 2$ regions). The effects of these factors on mortality were investigated. Most of the patients with gunshot wounds were brought to our emergency clinic by "112" emergency ambulance. Other injured patients were referred to ED by their relatives and a small number of them were referred from other medical centers. Patients who died outside the hospital were excluded from the study.

Ethical Aspect: Ethical approval was obtained from the Ethics Committee of Van Yüzüncü Y1l University Faculty of Medicine with the number (B.30.2.YYU.0.01.00.00/63).

Statistical Analysis: Descriptive statistics for the continuous variables were presented as Mean, Standard deviation, minimum and maximum values while count and percentages for categorical variables. One-way ANOVA was used to compare group means. Duncan multiple comparison test was also used to identify different group means followed by ANOVA. For determination linear relationships among the variables, Pearson correlation analysis was carried out. In addition, chi-square test was performed to determine the relationship between categorical variables. Statistical significance level was considered as 5\% and SPSS (ver: 21) statistical program was used for all statistical computations.

\section{Results}

There were a total of 246 subjects included in the study: $211(85.8 \%)$ males and $35(14.2 \%)$ females. The average age was $29.07 \pm 13.5$ (6-70). The FAI cases were most prevalent in August 56 (22.7\%) and least prevalent in February (1.6\%) (Fig. 1).

Extremity (43\%) and head/neck region (21.5\%) were the most frequently injured regions in terms of injury localizations. The organ injuries were as follows: the lung pathologies were 23 cases of hemopenumothorax $(9.3 \%), 9$ cases of pneumothorax (3.6\%); the abdomen pathologies were 20 cases of intestine perforation in the abdomen $(8 \%), 9$ cases of liver laceration (3.6\%); the head pathologies were 15 cases of brain injuries and hemorrhage (6\%), 9 cases of maxillofacial injury (3.6\%), 8 cases of eye perforation $(3.2 \%)$, the upper/lower extremity injuries were 67 cases of bone fractures $(27.2 \%)$. The most common injury findings were fractured bones $(27.2 \%)$, followed by lung traumas $(13 \%)$ and head and face traumas $(13 \%)$ (Table 1). 14 patients that were in bad condition upon arrival to the ED (cases with hypotension, changes in consciousness or

East J Med Volume:25, Number:1, January-March/2020 
Table 1. Total number of organ injuries due to firearm injuries

\begin{tabular}{lcc}
\hline Injury Localizations & Number & \% Percent \\
\hline Head and face injuries & 53 & 21.5 \\
Cranium fracture & 17 & 6.9 \\
Subdural hemorrhage & 7 & 2.8 \\
Epidural hemorrhage & 4 & 1.6 \\
Subarachnoid hemorrhage & 16 & 6.5 \\
Jaw fracture & 5 & 2 \\
Cervical vertebra fracture & 4 & 1.6 \\
Pulmonary injuries & 35 & 14.2 \\
Pneumothorax & 9 & 3.6 \\
Hemothorax & 2 & 0.8 \\
Hemopneumothorax & 23 & 9.3 \\
Lung Contusion & 4 & 1.6 \\
Rib fracture & 6 & 2.4 \\
Diaphragm laceration & 2 & 0.8 \\
Abdominal injuries & 27 & 10.9 \\
Bowel perforation & 20 & 8.1 \\
Liver laceration & 9 & 3.6 \\
Spleen laceration & 6 & 2.4 \\
Stomach perforation & 5 & 2 \\
Bladder perforation & 3 & 1.2 \\
Upper Extremity & 42 & 17 \\
Lower extremity & 64 & 26 \\
Pelvis & 4 & 1.6 \\
\hline
\end{tabular}

shortness of breath) were immediately taken into operation. In one case of abdominal trauma, the blood pressure could not be measured due to excessive blood loss, caused by injury to a major blood vessel. This patient died in the ED despite the medical interventions.

The patients' levels of consciousness were evaluated with the Glasgow coma scale (GCS). The results were as follows: 31 patients scored 3-8, 22 patients scored 9-13, 193 patients scored 14-15 (Table 2).

When we examined the GCS scores of the 28 patients who died, it was determined that 24 out of the 31 patients with scores between 3-8 (77.4\%) [especially 18 of the 19 patients with scores between 3-4 (95\%)], and 4 of the 22 patients with scores between, 9-13 $(18 \%)$ had died.

It was determined that the internalized patients were mostly hospitalized in the Orthopedics and Traumatology, and the Anesthesiology clinics. The clinic that received the smallest amount of internal transfers was the Cardiovascular Surgery clinic (Table 3).

The length of stay in the emergency department was as follows; head and neck 119, thorax 150, lower extremity 148, upper extremity 132, abdomen 134, multiple trauma 161 and ex 55. GCS and Hb levels and length of stay in the ED were correlated with mortality ( table 4).

As a result, 204 patients were successfully discharged, 28 patients died, 13 patients were transferred and 1 patient refused treatment.

\section{Discussion}

Firearm injuries are a global public health problem. Non-fatal firearm injuries have different rates compared to fatal ones. On average, two out of every seven firearm injuries consist of fatal and five nonfatal injuries (8). The FAIs are an independent risk factor with high morbidity and mortality rates. Most of the injured patients either died at the scene or transferred to the hospital or died at ED in the first minutes of treatment (5). The most important finding of our study was that low GCS and Hb levels, length of stay in the ED had an impact on mortality and mortality rates were higher. There was a significant relationship between low GCS and death $(\mathrm{p}<0.001)$. The neurological examination findings are defined as determinants of prognosis in the literature. It is known that GCS results play a part in mortality. This scale is a simple and useful method for evaluating the morbidity and mortality of the patient. It is positively 
Mehmet Reşit Öncü / Increasing mortality in gunshot wounds

Table 2. Glaskow Coma Score (GCS)

\begin{tabular}{lllll}
\hline GCS & Number & $\%$ Percent & Number of deaths & $\%$ Percent \\
\hline $3-8$ & 31 & 12.6 & 24 & 77.4 \\
$9-13$ & 22 & 8.9 & 4 & 18 \\
$14-15$ & 193 & 78.5 & 0 & 0 \\
\hline
\end{tabular}

Table 3. Distribution of inpatients treated according to clinics

\begin{tabular}{lcc}
\hline Clinics & Number & \% Percent \\
\hline Anesthesia Intensive Care & 31 & 12.6 \\
Brain surgeon & 7 & 2.8 \\
General Surgery & 21 & 8.5 \\
Chest Surgery & 29 & 11.7 \\
Eye diseases & 8 & 3.2 \\
Cardiovascular surgeon & 6 & 2.4 \\
Orthopedics and Traumatology & 77 & 31.3 \\
Plastic surgery & 25 & 10.2 \\
Child Surgery & 7 & 2.8 \\
\hline
\end{tabular}

Table 4. Interpretation of Pearson correlation coefficients

\begin{tabular}{lcccc}
\hline & Long-term ED & Age & Hb & GCS \\
\hline Long-term ED / min & 1 & & & \\
Age / year & 0.092 & 1 & & \\
$\mathrm{Hb} / \mathrm{g} / \mathrm{dl}$ & 0.122 & 0.091 & 1 & \\
$\mathrm{GCS}$ & $0.205^{* *}$ & 0.071 & $0.335^{* *}$ & 1 \\
\hline
\end{tabular}

** Correlation is significant at the 0.01 level

correlated with the severity of the head trauma. In our study, $77.4 \%$ of patients who scored $3-8$ on GCS died, and $95 \%$ of patients who scored 3-4 points died. The mortality rate was $18 \%$ for the patients who scored 9-13. Deng et al. they reported that the risk of death was greatest in patients with a GCS score of 3-8 (9). Murphy et al. have determined that the mortality rates were $70 \%$ for the patients who scored lower than 9 on the GCS scale and who had central nervous system paralysis (10). Brandvold et al. have determined that the mortality rate was $80 \%$ for patients who scored 3-4 on the GCS scale, $12 \%$ for the patients who score $5-12$, and $6 \%$ for the patients who score 13-15 (11). Eriş et al. have indicated that $82.4 \%$ of the patients with a GCS score of $0-7$ and $12 \%$ of the patients with a GCS score of $8-12$ have died (12). Our results regarding the relationship between GCS and mortality rates were consistent with the literature data.

The literature shows that hemorrhagic shock is the most important cause of premature death. It is characterized by low Hb levels. It is the hemorrhagic shock which is the result of major vascular injuries that determines the relationship between hypotension and increased mortality. In our study, the lowest levels of $\mathrm{Hb}$ levels were in multiple traumas accompanied by abdominal and lower extremity, abdominal and chest injuries. There was a significant relationship between low $\mathrm{Hb}$ and death $(\mathrm{p}<0.001)$. Eriş et al. have found that $82 \%$ of the patients who had died had shock status when they had applied to the hospital. This result was statistically significant (12). In the late phases, the mortality can be caused by septic shock or multiple organ failures. Cooka et al. have conducted a study in the United States between 2006 and 2010 and they have found that approximately 385.769 people applied to the EDs and 141.914 people were hospitalized due to FAI. The hospitalization rates of the male patients are nine times higher than the female patients. However, the mortality rates of the male patients are lower (13).

We investigated the relationship between the place of injury and death in gunshot wounds and the most common injury sites. In our study, when we examined the location of body injuries, FAI-related mortality rates were $60.7 \%$ of head and neck, $21.4 \%$ of abdomen, $10.7 \%$ of thoracic-abdomen, $7.2 \%$ of thoracic. In the literature, mortality rates associated with FAI were calculated separately as head and neck, chest, abdominal and extremity injuries. There are

East J Med Volume:25, Number:1, January-March/2020 
several studies that deal with the body as a whole. Karaca et al. have determined the mortality rates related to FAIs to be $41 \%$ for head and neck traumas, $5.5 \%$ for thorax traumas, and $25 \%$ for abdominal traumas. Also, considering radiological findings, the mortality rates for critical injuries were as follows: $90 \%$ for intracranial injuries, $20 \%$ for thoracic injuries, and $36 \%$ for intra-abdominal injuries. It is observed that the mortality rates are significantly higher for intracranial injuries (6). Süslü et al. have calculated the mortality rates for patients with head injuries (FAI) to be as follows: $90 \%(29 / 32)$ for patients with coagulopathies, $25 \%(4 / 16)$ for the patients without coagulopathies (14). Several studies indicate the FAI-related mortality rates to be $23-90 \%$ for cranial injuries, $14-37 \%$ for thorax injuries, $3-31 \%$ for abdominal injuries. The mortality rate was found to be $15 \%$ for the body overall (12). Zebib et al. have determined the injury localizations and their rates due to firearms to be as follows: abdomen $19.3 \%$, chest $11.3 \%$, head $5.5 \%$, pelvis $5.4 \%$, lower extremity $15.9 \%$, upper extremity 3.3\% (15). Kelly et al. In their study, the mortality rate due to FAI was $18.6 \%(\mathrm{n}=$ 11), $13.5 \%(n=8)$ in the chest, and $5 \%(n=3)$ in the head and neck vascular spaces (16).

We investigated the relationship between gunshot injuries and seasonal temperature. In our study, we have determined that FAI incidences increase in the months when temperatures are higher. The prevalence of FAIs was highest in August (22.7\%) and lowest in February (1.6\%). Kieltya et al. have studied the distribution of FAIs according to months and years, and they have concluded that the increase in the maximum daily temperature causes an increase in the daily incidences of FAI and crimes related to firearms (3). Baduroğlu et al. have determined that the most FAI incidences were in September and October, and the least were in February (17). According to the literature results, we concluded that gunshot wounds and seasonal temperature changes may affect human mood. hence there may be an increase in the number of gunshot injuries during the hot seasons

In addition, $67 \%$ of all FAI patients were hospitalized, and the mortality rate was $15.4 \%$ (12). Kelly et al. have determined the FAI-related death rate to be $18.6 \%(\mathrm{n}=11)$. These were divided into thoracic $(13.5 \%, \mathrm{n}=8)$ and head/neck vascular injuries $(5 \%, \mathrm{n}=3)(16)$. The rates of injuries according to localization for our study are as follows: extremities $43 \%$, head and neck $21.5 \%$, thorax $14.2 \%$ abdomen $10.9 \%$. When the organ-specific injuries are evaluated, Erdik et al. have found that the most common thorax-related pathologies to be hemopneumothorax (43\%), lung contusion (43\%) and hemothorax (27\%). They also found that the most common reason of mortality was injury to major blood vessels (18). Oymac1 et al. have determined that the most frequent intra-abdominal injuries were located in the colon, the small intestine, the liver and the biliary ducts respectively (19). Eriş et al. have indicated that $16.8 \%$ of abdominal injuries resulted in mortality. The most commonly injured organs were determined to be the small and large intestines (12).

Limitation(s): It is a limitation of our study that the infections are not investigated, as they are an important risk factor for mortality. Also, the reason for low mortality rates in the ED may be due to the successful initial treatment or because the patient is urgently hospitalized due to the urgency of their situation.

The most important finding of our study was that low GCS and Hb levels, length of stay in the ED had an impact on mortality and mortality rates were higher. In particular, intracranial hemorrhages, main vessel injuries, abdominal injuries, high mortality rate can be. FAIs should be treated with the work of the interdisciplinary trauma team. Initial treatment should be performed as specified in the Advanced Trauma Life Support protocol.

\section{References}

1. Erkol Z. Analysis of Firearm Injuries in Gaziantep Province. 1st National Congress of Forensic Medicine, Congress Book, Istanbul, 1-4 November 1994; 267-272.

2. Elfawal MA, Awad OA. Firearm Fatalities in Eastern Saudi Arabia, İmpact of Culture and Legislation. Am J. Forensic Med. Pathol 1997; 18: 391-396.

3. Kieltyka J, Kucybala K, Crandall M. Ecologic factors relating to firearm injuries and gun violence in Chicago. J Forensic Leg Med. 2016; 37: 87-90.

4. Spitzer SA, Staudenmayer KL, Tennakoon L, et al. Costs and Financial Burden of Initial Hospitalizations for Firearm Injuries in the United States, 2006-2014. Am J Public Health 2017; 107: 770-774.

5. Cook PJ, Rivera-Aguirre AE, Cerdá $\mathrm{M}$, et al. Constant Lethality of Gunshot Injuries From Firearm Assault: United States, 2003-2012. Am J Public Health 2017; 107: 1324-1328.

6. Karaca M.A, Kartal N.D, Erbil B, et al. Evaluation of gunshot wounds in the emergency department. Ulus Travma Acil Cerrahi Derg 2015; 21: 248-255.

7. Alkan M. Evaluation of the unintentional firearm deaths and injuries in rural areas. Biomedical Research 2017; 28: 2379-2383. 
8. Omoke N.I. Analysis of Risk Factors for Gunshot Wound Infectionin a Nigerian Civilian Trauma Setting. World J Surg 2016; 40: 1885-1891.

9. Adult Firearm-Related Traumatic Brain Injury in United States Trauma Centers. Deng H, Yue JK, Winkler EA, Dhall SS, Manley GT, Tarapore PE. J Neurotrauma 2019; 36: 322-337.

10. Murphy JA, Lee MT, Liu X, et al. Factors affecting survival following self-inflicted head and neck gunshot wounds: a single-centre retrospective review. Int. J. Oral Maxillofac. Surg 2016; 45: 513-516.

11. Brandvold B, Levi L, Feinsod M, et al. Geonge. Penetrating craniocerebral injuries in the Israeli involvement in the Lebanese conflict, 1982-1985. Analysis of a less aggressive surgical approach. J Neurosurg 1990; 72: 15-21.

12. Eriş $\mathrm{S}$, Orak $\mathrm{M}, \mathrm{Al} \mathrm{B}$, et al. Factors affecting mortality in patients with gunshot injuries. Marmara Med J 2009; 22: 181-191.

13. Cooka A, Oslerb T, Hosmerc D, et al. Gunshot wounds resulting in hospitalization in the United States: 2004-2013. Int. J. Care Injured 2017; 48: 621-627.

14. Süslü HT, Çelikoğlu E, Çeçen A, et al. A statistical analysis for the identification of factors effecting prognosis of civilian patients with cranial gunshot wounds. Ulus Travma Acil Cerrahi Derg 2005; 11: 206-211.

15. Zebib L, Stoler J, Zakrison T.L. Geodemographics of gunshot wound injuries in Miami-Dade county, 2002-2012. BMC Public Health 2017; 17: 174.

16. O'Kelly F, Gallagher T. K, Lim K. T, et al. Gun Shot-101: an 8-year review of gunshot injuries in an Irish teaching hospital from a general surgical perspective. Ir J Med Sci 2010; 179: 239-243.

17. Baduroğlu E, Fedakar R, Durak D, et al. Evaluation of Patients with Firearm-Related Extremity Injuries Admitted to 3rd Stage Health Care Centers in Bursa. Uludağ Üniv Tip Fak Derg 2011; 37: 149-153.

18. Erdik O, Karasu S, Haberal İ, et al. Our surgical experience with thoracic gunshot injuries: Evaluation of 258 patients. Turkish J Thorac Cardiovasc Surg 2007; 15: 59-63.

19. Oymacı E, Kapkaç M, Uçar Y, et al. The effects of gunshot and shotgun wounds to mortality and morbidity. Ulus Travma Acil Cerrahi Derg 2007; 2: 132-136. 